\title{
On trade, land-use, and biodiversity
}

\author{
Stephen Polasky, ${ }^{\mathrm{a}, *}$ Christopher Costello, ${ }^{\mathrm{b}}$ and Carol McAusland ${ }^{\mathrm{c}}$ \\ ${ }^{a}$ Department of Applied Economics, University of Minnesota, 337E Classroom Office Building, \\ 1994 Buford Avenue, St. Paul, MN 55108, USA \\ ${ }^{\mathrm{b}}$ Donald Bren School of Environmental Science and Management, UC Santa Barbara, Santa Barbara, CA, USA \\ ${ }^{\mathrm{c}}$ Department of Economics and Donald Bren School of Environmental Science and Management, \\ UC Santa Barbara, Santa Barbara, CA, USA
}

Received 30 December 2002; revised 28 July 2003; accepted in revised form 10 November 2003

\begin{abstract}
We combine a simple trade model with a species-area curve to derive the effect of trade on biodiversity conservation. Trade causes specialization in production that drives specialization in ecosystems and their associated biodiversity. When trading partners contain similar species in autarky, trade has little effect on global biodiversity but lowers local biodiversity. On the other hand, with high endemism, specialization causes significant declines in both local and global biodiversity. If preferences for biodiversity conservation are sufficiently high, overall utility may decline with a move toward free trade unless corrective conservation policy is instituted.
\end{abstract}

(C) 2003 Elsevier Inc. All rights reserved.

Keywords: Species-area curve; Conservation; Biodiversity; Endemism; Specialization

\section{Introduction}

Human actions have been linked to a rapid increase in the rate of species extinctions and loss of biodiversity (e.g., [14,39]). Though it is difficult to establish extinction rates with much precision, most estimates find an increase of several orders of magnitude in the current rate of extinction above the historical rate $[25,26]$. Human activities threaten biodiversity in a number of ways including habitat loss, the introduction of exotic species, changes in climate and biogeochemical cycles, pollution, and over-harvesting. Of these, habitat loss and the introduction of exotic species are blamed for causing the vast majority of current biodiversity loss [38,40].

Patterns of trade affect habitat loss through the conversion of land for economically productive uses such as agriculture (crops and grazing), forestry and expansion of urban areas. Conversion of

\footnotetext{
${ }^{*}$ Corresponding author. Fax: + 1-612-625-2729.

E-mail address: spolasky@apec.umn.edu (S. Polasky).
} 
natural habitat into agricultural fields, managed forests or other human dominated land use will occur where it is profitable to do so. Profitability of activities is affected by prices which are, in turn, affected by trade. Trade can impact biodiversity by changing the magnitude and geographical location of production and land use, thereby determining which lands are converted and which are maintained as natural habitat.

We analyze the effects of trade on land use and trace the likely effects of these on biodiversity conservation. This paper contributes to two largely distinct literatures. The first is the growing economics literature on biodiversity conservation planning. The most relevant work in this area analyzes the economic and biodiversity conservation consequences of land use decisions emphasizing the tradeoff between economic activity and habitat conservation. Ando et al. [2] analyze cost-effective strategies for choosing biological reserves to conserve listed species under the Endangered Species Act. Polasky et al. [27] conduct a similar analysis for conserving terrestrial vertebrates in Oregon. Montgomery et al. [20] analyze land use allocation at a county level and trace out a cost curve for conserving species. Several papers analyze the tradeoff between the value of timber production and species conservation in forested landscapes (e.g., $[3,6,10,15,24])$ or the opportunity cost of protecting an endangered species (e.g, [12,18,19]).

Secondly, there is the growing body of work concerned with the impacts of international trade on the environment. International economics has long recognized that trade liberalization may reduce welfare if domestic market failures - of which environmental externalities are a prime example - are not corrected. Numerous authors have examined this problem in the context of local and transboundary pollution arising from industrial activity; see for example [1,8,28]. Among other things, they show that a country can be made worse off by engaging in trade if liberalization causes an expansion of under-regulated industries domestically or shifts production of pollution intensive goods to countries with weaker environmental standards. Other papers focus on the impact of trade liberalization on patterns of resource use. For example, Chichilnisky [7] and Brander and Taylor [5] show that trade liberalization with incomplete property rights can lead to resource depletion outweighing conventional gains from trade. Barbier and Schulz [4] and Kohn and Capen [13] examine the relationship between trade policy and biodiversity. Barbier and Schulz [4] analyze how international transfers and trade interventions affect a countries resource harvest and land conservation decisions; they explicitly incorporate the species-area curve into their bioeconomic model, however they do not consider biodiversity in more than a single country. Kohn and Capen [13] characterize the optimal volume of trade when governments use efficient pollution and trade taxes; they treat all land within a country as generic and proxy environmental quality by the sum of species occurring in each country (thereby ignoring issues surrounding endemism and the contribution of local species diversity to welfare).

The paper is organized as follows. In Section 2 we present a simple two-good two-country trade model. The two goods in the model, grain and timber, are each produced by a fixed ratio of labor and land. Only certain lands (habitat types) are capable of producing each good. Land not converted for production remains as natural habitat capable of supporting species. How many species remain is determined by a species-area curve relationship [17]. In Section 3, we compare equilibrium production, consumption, and land use in autarky versus free trade. We show that the increased specialization associated with trade can have important consequences for patterns of habitat conversion. Specialization in production, because it requires heavy use of certain habitat, causes a decline in species conserved within a country. This result obtains from the concavity of 
the species area relationship and a version of Jensen's Inequality. Depending upon the degree of overlap of species between the two countries, global biodiversity can either increase or decrease with specialization. With a high degree of endemism (i.e., low overlap of species across countries), trade that results in increased specialization will cause a decline in global species conserved.

Though trade will necessarily increase the production of goods and the utility of consumption, it may lead to a decline in overall utility. This result occurs when trade leads to large reductions in species conservation, either locally or globally, and such losses factor heavily into the utility function. Section 4 considers regulating trade to maximize utility where a regulator takes account of species concerns. We show that taking species conservation concerns into account can reduce specialization and may reduce the overall level of production in order to leave more habitat intact. Section 5 contains concluding comments.

\section{A simple trade-conservation model}

\subsection{Production}

In this paper we use a variation on the standard Specific Factors model of trade. Each country $i$, $i=1,2$, has a fixed endowment of labor that may be employed in harvesting either timber, $X$, or grain, $Y$. Denote by $\bar{L}_{i}$ country $i$ 's total endowment of labor, which we assume also equals its population, and by $L_{F i}$ the amount of labor allocated to harvesting timber and by $L_{G i}$ the amount of labor allocated to harvesting grain.

We assume that use of each type of land is free. It is straightforward to show that, under reasonable assumptions, this generates a Leontief production structure in each sector: in order for each worker to produce grain or timber she requires exclusive access to one unit of converted land. ${ }^{1}$ Producing timber requires one unit of converted forest land. Producing grain requires one

\footnotetext{
${ }^{1}$ Suppose $X=F(L, T)$ and $Y=G(L, T)$ where $F$ and $G$ are linearly homogeneous in $L$ and $T$; we drop the country subscripts for now. Assuming producers in each sector take input and output prices as given then input choices are the result of standard cost minimization problems. For example, in the timber industry, cost minimizing unit-input requirements $v_{L X}, v_{T X}$ solve

$$
\min _{v_{L X}, v_{T X}} w v_{L X}+r v_{T X} \quad \text { s.t. } F\left(v_{L X}, v_{T X}\right) \leqslant 1
$$

where $r$ is the rental price of land. When $r=0$, linear homogeneity of the production function permits the revision of Eq. (1) as

$$
\min _{v_{L X}, t_{X}} w v_{L X} \quad \text { s.t. } v_{L X} f\left(t_{X}\right) \leqslant 1
$$

where $f\left(t_{X}\right) \equiv F\left(1, t_{X}\right)$ and $t_{X} \equiv \frac{v_{T X}}{v_{L X}}$ is the land-labor ratio in the timber sector. Treating the constraint as binding allows the further revision of the cost-minimization problem as an unconstrained optimization: $\min _{t_{X}} \frac{w}{f\left(t_{X}\right)}$ with the associated first-order condition for an interior optimum

$$
-\frac{w f^{\prime}\left(t_{X}\right)}{f\left(t_{X}\right)^{2}}=0 .
$$

Provided $f^{\prime}\left(t_{X}\right)$ equals zero at some finite $t_{X}$-i.e. at some finite land-labor ratio the marginal productivity of labor cannot be raised by simply complementing workers with even more land - then the solution to Eq. (2), and thus the cost minimizing unit input requirements, are independent of $w$ and hence also independent of output prices. In sum, when
} 
unit of converted grassland. Denote each country's fixed endowment of forest and grassland, respectively, by $T_{F i}$ and $T_{G i}$. Let the output of a worker in country $i$ be $a_{i}$ units of $X$ if she works on forest land and $b_{i}$ units of $Y$ if she works on grassland.

\subsection{Species assemblages}

We assume that once land is converted to a productive use, it is incapable of supporting native biological diversity. While certainly an oversimplification, this assumption helps maintain clarity and is not entirely unrealistic. For example, the tall grass prairies of the midwestern US once supported large assemblages of native species; statewide declines in tallgrass prairie from historical area coverage range from an $82.6 \%$ decline (Kansas) to a $99.9 \%$ decline (Illinois, Indiana, Iowa, North Dakota, Wisconsin) [29]. Subsequent conversion to crop monocultures supports very low biological diversity; as of 2001, 740 plant species had been listed as either threatened or endangered under the US Endangered Species Act [36]. In our model, land not in production remains as natural habitat capable of supporting species. Define natural forest and grassland habitat in country $i$ as $T_{F i}^{N}=T_{F i}-L_{F i}$ and $T_{G i}^{N}=T_{G i}-L_{G i}$, respectively. For simplicity we assume $\bar{L}_{i} \leqslant \min \left\{T_{F i}, T_{G i}\right\}$ for each country $i$.

A widely utilized first-principle in ecological theory is the relationship between the size of habitat and the number of species it can support [17]. The "species area curve" describes the number of species surviving in each habitat type. Denote by $S_{F i}$ the number of forest land species in country $i$ and by $S_{G i}$ the number of grassland species; then

$$
\begin{aligned}
& S_{F i}=\phi_{i}\left(T_{F i}^{N}\right), \\
& S_{G i}=\gamma_{i}\left(T_{G i}^{N}\right),
\end{aligned}
$$

where $\phi_{i}(\cdot)$ and $\gamma_{i}(\cdot)$ are the species-area functions in country $i$ for forest and grassland ecosystems, respectively. Species-area curves have declining marginal returns to area so $\phi_{i}^{\prime}>0, \gamma_{i}^{\prime}>0$ and $\phi_{i}^{\prime \prime}<0, \gamma_{i}^{\prime \prime}<0$. Although biological diversity can be measured in many ways (see for example, $[9,31,37])$, we will focus attention only on species richness. The number of species conserved in country $i$ is therefore $S_{i}=S_{F i}+S_{G i}$. Define $S$ to be the number of species conserved globally.

\subsection{Citizen-consumers}

We round out the model by assuming that consumers in each country have identical CobbDouglas preferences over timber and grain and separable utility over consumption goods and species conservation: $U\left(x_{i}^{\alpha} y_{i}^{1-\alpha}, S_{i}, S\right)$ where $\alpha \in(0,1)$ and $x_{i}$ and $y_{i}$ are per capita consumption levels in country $i$. Optimization by atomistic consumers yields relative demand for timber $\frac{x^{d}}{y^{d}}=$ $\frac{\alpha}{[1-\alpha] P}$ where $P$ is the local relative price of timber.

(footnote continued)

$r=0$ the cost minimizing land-labor ratio is fixed and independent of other prices. Normalizing the units by which land is measured then gives the fixed land-labor ratio $t_{X}=1$ assumed in the model; the maintained assumption that $r=0$ follows provided the economy's labor endowment is sufficiently small relative to its land endowments - as we assume explicitly in p. 8 . 
Note that the utility function admits both local species conserved and global species conserved to be valued. Local species conservation may be valued because people place value on observing wildlife (e.g., birdwatching) or because species contribute to the production of valued ecosystem services. Increasing diversity has been linked to increased ecosystem productivity, nutrient retention, stability and other ecosystem functions that may produce valued ecosystem services [11,16,22,23,32-35]. Global species conservation may be of value because people may wish to preserve the evolutionary potential of species, to preserve the genetic material of the species for bioprospecting purposes [30], or because people place existence value on species that is unrelated to any present or future potential use value of the species. Of course, people may also care about other attributes of biodiversity that are not closely linked to either local or global species richness. For example, people may place great value on certain species (e.g., charismatic megafauna) and little value on other species (e.g., charismatically challenged invertebrates with no known economic use). We return to the issue of alternative values of biodiversity briefly in the final section of the paper.

\section{Results}

In this section we solve for both species assemblages and consumer utility in autarky and the open economy. Our objective is to derive the effects of trade on biodiversity and overall utility.

\subsection{Autarkic equilibrium}

Denote autarkic values by superscript 0 . Given the Cobb-Douglas preferences for private goods and the Leontief structure of production, in autarky equilibrium requires $P_{i}^{0}=\frac{b_{i}}{a_{i}}$ and $L_{F i}^{0}=\alpha \bar{L}_{i}$ and so $X_{i}^{0}=a_{i} \alpha \bar{L}_{i}$ and $Y_{i}^{0}=b_{i}[1-\alpha] \bar{L}_{i}$. This implies that the number of forest species present in country $i$ will be $S_{F i}^{0}=\phi_{i}\left(T_{F i}-\alpha \bar{L}_{i}\right)$ and the number of grassland species present will be $S_{G i}^{0}=\gamma_{i}\left(T_{G i}-[1-\alpha] \bar{L}_{i}\right)$. And finally, these autarkic values imply that the utility of any one of country $i$ 's $\bar{L}_{i}$ citizens is $U_{i}^{0}=U\left(u_{i}^{0}, \phi_{i}\left(T_{F i}-\alpha \bar{L}_{i}\right)+\gamma_{i}\left(T_{G i}-[1-\alpha] \bar{L}_{i}\right), S\right)$ where $u_{i}^{0}=\alpha^{\alpha}[1-$ $\alpha]^{1-\alpha} a_{i}^{\alpha} b_{i}^{1-\alpha}$ is the (sub-) utility that a citizen of country $i$ obtains from consumption of grain and timber in autarky.

\subsection{Free trade}

We now consider the equilibrium allocations of labor across industries when countries are open to free trade (denoted by ${ }^{*}$ ). We assume, without loss of generality, that country 1 has a comparative advantage in production of timber while country 2 has comparative advantage in the production of grain: $\frac{b_{2}}{a_{2}}>\frac{b_{1}}{a_{1}}$. Consider the case in which each country is specialized in the free trade equilibrium. ${ }^{2}$ When each country is specialized then country 1 allocates all of its labor to

\footnotetext{
${ }^{2}$ This result will occur if $\frac{a_{2}}{a_{1}} \leqslant \frac{[1-\alpha] \bar{L}_{1}}{\alpha \bar{L}_{2}} \leqslant \frac{b_{2}}{b_{1}}, \bar{L}_{1} \leqslant T_{F 1}$ and $\bar{L}_{2} \leqslant T_{G 2}$.
} 
extraction of timber while all workers in country 2 are employed in the production of grain: $L_{F 1}=\bar{L}_{1}$ and $L_{G 2}=\bar{L}_{2}$.

Then the number of species in each country will be

$$
\begin{aligned}
& S_{F 1}^{*}=\phi_{1}\left(T_{F 1}-\bar{L}_{1}\right), \\
& S_{G 1}^{*}=\gamma_{1}\left(T_{G 1}\right), \\
& S_{F 2}^{*}=\phi_{2}\left(T_{F 2}\right), \\
& S_{G 2}^{*}=\gamma_{2}\left(T_{G 2}-\bar{L}_{2}\right)
\end{aligned}
$$

and so the total number of species in each country is

$$
\begin{aligned}
& S_{1}^{*}=\phi_{1}\left(T_{F 1}-\bar{L}_{1}\right)+\gamma_{1}\left(T_{G 1}\right), \\
& S_{2}^{*}=\phi_{2}\left(T_{F 2}\right)+\gamma_{2}\left(T_{G 2}-\bar{L}_{2}\right) .
\end{aligned}
$$

This gives overall utility of

$$
U_{1}^{*}=U\left(u_{1}^{*}, \phi_{1}\left(T_{F 1}-\bar{L}_{1}\right)+\gamma_{1}\left(T_{G 1}\right), S\right)
$$

in country 1 and

$$
U_{2}^{*}=U\left(u_{2}^{*}, \phi_{2}\left(T_{F 2}\right)+\gamma_{2}\left(T_{G 2}-\bar{L}_{2}\right), S\right)
$$

in country 2 where $u_{1}^{*}=\alpha a_{1}^{\alpha} b_{2}^{1-\alpha} \bar{L}_{1}^{\alpha-1} \bar{L}_{2}^{1-\alpha}$ and $u_{2}^{*}=[1-\alpha] a_{1}^{\alpha} b_{2}^{1-\alpha} \bar{L}_{1}^{\alpha-1} \bar{L}_{2}^{1-\alpha} \cdot{ }^{3}$

\subsection{The effects of trade}

From trade theory, we know that moving from autarky to free trade will increase welfare in a world without other distortions or imperfections. In this model, opening up to trade unambiguously increases the (sub-) utility from consumption of private goods. With other market failures, however, trade liberalization may not result in an increase in welfare. Here we trace out the effects of a move from autarky to free trade on local biodiversity, global biodiversity and overall utility, in turn.

\subsection{1. "Local" biodiversity}

Whether the number of native species surviving in country 1 is higher or lower in the free trade equilibrium depends on whether

$$
S_{1}^{0}=\phi_{1}\left(T_{F i}-\alpha \bar{L}_{i}\right)+\gamma_{1}\left(T_{G i}-[1-\alpha] \bar{L}_{i}\right) \gtreqless \phi_{1}\left(T_{F 1}-\bar{L}_{1}\right)+\gamma_{1}\left(T_{G 1}\right)=S_{1}^{*} .
$$

Because country 1 specializes in timber production, fewer forest species but a greater number of grassland species are present in the trading equilibrium. Whether the gain in grassland species is sufficient to offset the loss in forest species depends on parameters of the model but some informative conclusions can be drawn. Take, for example, the simplest case in which labor and land are equal across ecosystems and countries $\left(\bar{L}_{i}=\bar{L}\right.$ and $T_{j i}=T$ for $\left.j=\{F, G\}, i=\{1,2\}\right)$, but that the species area relationships differ between countries and ecosystems according to a multiplicative scaling factor: $\phi_{i}(\cdot)=c_{i} \phi(\cdot)$ and $\gamma_{i}(\cdot)=d_{i} \phi(\cdot)$ for $i=\{1,2\}$. Whether trade tends to increase or decrease biodiversity depends critically on how productive their ecosystems are in

\footnotetext{
${ }^{3}$ These values follow from the free trade equilibrium price $P^{*}=\frac{\alpha b_{2} \bar{L}_{2}}{[1-\alpha] a_{1} \bar{L}_{1}}$.
} 
producing species. If countries have symmetric species area relationships, trade unambiguously reduces local biodiversity. On the other hand if the species area relationships across countries are sufficiently asymmetric, trade may increase local biodiversity. These results are summarized in the following proposition:

Proposition 1. When countries are symmetric in their endowments of land and labor, but their species area relationships differ up to a scaling parameter, we obtain the following results:

- For any $c_{1}$ there exists a unique $\tilde{d}_{1}\left(c_{1}\right)$ satisfying $c_{1}<\tilde{d}_{1}\left(c_{1}\right)<\infty$ such that if $d_{1}\left[\begin{array}{l}< \\ >\end{array}\right] \tilde{d}_{1}$, local biodiversity is $\left[\begin{array}{l}\text { decreased } \\ \text { increased }\end{array}\right]$ with free trade. And,

- For any $c_{2}$ there exists a unique $\tilde{d}_{2}\left(c_{2}\right)$ satisfying $0<\tilde{d}_{2}\left(c_{2}\right)<c_{2}$ such that if $d_{2}\left[\begin{array}{l}< \\ >\end{array}\right] \tilde{d}_{2}$, local biodiversity is $\left[\begin{array}{l}\text { increased } \\ \text { decreased }\end{array}\right]$ with free trade.

Proof. We prove the result for country 1. A similar proof exists for country 2. The difference in local biodiversity under autarky and free trade is

$$
S_{1}^{0}-S_{1}^{*}=c_{1} \phi(T-\alpha \bar{L})+d_{1} \phi(T-(1-\alpha) \bar{L})-\left(c_{1} \phi(T-\bar{L})+d_{1} \phi(T)\right) .
$$

First we show how the difference in local biodiversity in autarky and local biodiversity under free trade changes with $d_{1}$ :

$$
\frac{d\left(S_{1}^{0}-S_{1}^{*}\right)}{d\left(d_{1}\right)}=\phi(T-(1-\alpha) \bar{L})-\phi(T)<0 .
$$

This expression is negative because $\phi^{\prime}>0$. Therefore, for any $c_{1}$, there exists at most one $\tilde{d}_{1}\left(c_{1}\right)$ such that $S_{1}^{0}=S_{1}^{*}$, and by the sign of Eq. (6), if $d_{1}\left[\begin{array}{l}> \\ <\end{array}\right] \tilde{d}_{1}\left(c_{1}\right), S_{1}^{0}\left[\begin{array}{l}< \\ >\end{array}\right] S_{1}^{*}$.

We now show that $\tilde{d}_{1}\left(c_{1}\right)$ lies strictly between $c_{1}$ and $\infty$. Solving (5) explicitly for the $d$ for which $S_{1}^{0}=S_{1}^{*}$ (i.e. for $\tilde{d}_{1}\left(c_{1}\right)$ ), we obtain:

$$
\tilde{d}_{1}\left(c_{1}\right)=c_{1}\left[\frac{\phi(T-\bar{L}+(1-\alpha) \bar{L})-\phi(T-\bar{L})}{\phi(T)-\phi(T-(1-\alpha) \bar{L})}\right] .
$$

The arguments of $\phi$ in (7) have been rearranged to show that the difference in the arguments of $\phi$ in both the numerator and denominator is $(1-\alpha) \bar{L}$. Therefore, since $\phi$ is both concave and increasing, the bracketed term in (7) is greater than 1 and $\tilde{d}_{1}\left(c_{1}\right)>c_{1}$. Furthermore, the numerator is always finite and the denominator is always positive, so $\tilde{d}_{1}\left(c_{1}\right)<\infty$.

The assumption that species area curves are identical up to a scaling parameter is widely accepted in ecology. The usual form of the species-area curve is that species equals $w L^{z}$, where $w$ is ecosystem-specific, but $z$ is constant across ecosystems (often, $z=0.25$ is used). Proposition 1 shows that unless the habitat type that is increasing in area is sufficiently more productive ecologically than the ecosystem that is reduced in area, then free trade will reduce local biodiversity. The intuition for this result is as follows: trade that causes specialization in production also causes specialization in habitats. Owing to the concavity of the species area relationship, the decline in habitat to produce the good in which the country specializes tends to 
cause a steep decline in biodiversity, while the increase in habitat toward complete restoration moves along a flatter portion of the species area curve and consequently tends to cause a small increase in biodiversity. With asymmetric species area relationships, specialization also causes a decrease in biodiversity unless the restored habitat is significantly more productive ecologically. The more concave is the species area relationship, the stronger is this effect.

We further note that intuitively, one may expect a positive relationship between $a_{i}$ (productivity of forest land for timber products) and $c_{i}$ (productivity of forest land for producing species) and similarly between $b_{i}$ and $d_{i}$. Given that country 1 specializes in forest production, this typically, but not always, implies $c_{1}<d_{1}$ and $c_{2}>d_{2}$, in which case, moving to free trade unambiguously reduces local biodiversity in both countries.

\subsection{2. "Global" biodiversity}

The effect of trade on global biodiversity depends on the degree to which species in each country are endemic. In this section we explore two extreme cases: (1) all species in each country are endemic (no species overlap) and (2) all species are represented in both countries (complete species overlap). More generally, we can think of species in each country providing services that enter a consumer's utility function. In that case, the question is whether those services are uniquely provided by species in each country. For example, even though species of sedges occur throughout the world, they are primarily valued for their capacity to filter water in wetland ecosystems, which confers primarily a local benefit. Therefore, although the sedge species itself may not be endemic, the services it provides has primarily a local benefit, and utility should be measured accordingly. On the other hand, it may be sufficient for utility purposes that the species exist somewhere but the location of its existence does not matter. Maintaining genetic information contained in the species would fall into this category as might existence values. For example, if people care only that the worldwide chimpanzee population is viable, then a viable population in the Congo is redundant to a population in Cameroon (ignoring the possibility that redundant populations have value as risk mitigation).

Although the degree of endemism varies throughout the world, most countries share a significant proportion of their biodiversity with other countries. Of the 21 most widely recognized "biodiversity hot spots" around the world, the percent of endemic species varies from $9 \%$ (Brazil's Cerrado has 1268 bird, mammal, reptile, and amphibian species, only 117 of which are endemic) to $78 \%$ (Madagascar has 987 vertebrate species, 771 of which are endemic) (authors' calculations based on [21]). To the extent that trade is driven by differences in endowments or technologies across countries, we may expect little overlap between species in countries 1 and 2 . On the other hand, the above arguments suggest that the services provided by those species may be similar in the two countries, even if the species themselves are unique. In determining the effect of trade on worldwide biodiversity, we consider both extremes.

When all species are endemic, worldwide biodiversity $(S)$ is simply $S_{1}^{0}+S_{2}^{0}$ in autarky and $S_{1}^{*}+S_{2}^{*}$ under free trade. We can use Proposition 1 to derive the conditions under which free trade decreases local biodiversity in both countries, which in this case means that global biodiversity declines. Under many reasonable conditions, free trade reduces global biodiversity when there is little or no overlap in species between trading countries. 
But what is the effect of free trade on global biodiversity when few species are endemic? The answer sharply contradicts the result when there exists high endemism. With complete species overlap, the change in global forest and grassland biodiversity with free trade are given by

$$
\begin{aligned}
& S_{F}=\max \left\{\phi_{1}\left(T_{F 1}-\alpha \bar{L}_{1}\right), \phi_{2}\left(T_{F 2}-\alpha \bar{L}_{2}\right)\right\}-\max \left\{\phi_{1}\left(T_{F 1}-\bar{L}_{1}\right), \phi_{2}\left(T_{F 2}\right)\right\}, \\
& S_{G}=\max \left\{\gamma_{1}\left(T_{G 1}-(1-\alpha) \bar{L}_{1}\right), \gamma_{2}\left(T_{G 2}-(1-\alpha) \bar{L}_{2}\right)\right\}-\max \left\{\gamma_{1}\left(T_{G 1}\right), \gamma_{2}\left(T_{G 2}-\bar{L}_{2}\right)\right\} .
\end{aligned}
$$

Under the assumptions of Proposition 1 and with symmetric ecosystems across countries, global biodiversity is unambiguously increased under free trade. Since countries are symmetric, specialization causes local species declines in one sector, but local species increases in the other. Since each country specializes in a different good, and under the assumption of no endemism, worldwide biodiversity is greater (but more specialized). In this case, we would expect to see high global biodiversity, but species existing in only one country, where they previously occurred in multiple countries.

This result raises a question of the timing of trade policies. Moving from pristine conditions to autarky causes local extinctions (extirpation). If trade is subsequently introduced, extirpated species may not be able to recolonize the local ecosystem, in which case, global biodiversity would be unchanged when moving from autarky to free trade.

\subsubsection{Overall utility}

To determine the overall effect on citizen's utility, we must more explicitly define the utility function. For simplicity, we assume that species conservation enters the utility function as a simple separable and linear function, as follows:

$$
U_{i}=\underbrace{x_{i}^{\alpha} y_{i}^{1-\alpha}}_{u_{i}}+\underbrace{\mu S_{i}+\theta S}_{v_{i}} .
$$

In this section, we explore the difference in $U_{i}$ under autarky and free trade, assuming that countries are symmetric in their endowment of labor and land and each country has symmetric ecosystems $\left(c_{i}=d_{i}=1\right)$.

As we discussed in Section 3.3, the difference in sub-utility from goods consumption is unambiguously higher under free trade. The corresponding difference in utility from species existence depends on whether species are all endemic (Eq. (11)) or are shared between both countries (Eq. (12)), as summarized below:

$$
\begin{aligned}
& v_{1}^{0}-v_{1}^{*}=(\mu+2 \theta)(\phi(T-\alpha \bar{L})+\phi(T-(1-\alpha) \bar{L})-(\phi(T-\bar{L})+\phi(T))), \\
& v_{1}^{0}-v_{1}^{*}=(\mu+\theta)(\phi(T-\alpha \bar{L})+\phi(T-(1-\alpha) \bar{L}))-(\mu(\phi(T-\bar{L})+\phi(T))+2 \theta \phi(T)) .
\end{aligned}
$$

Whether citizens obtain higher utility under autarky or free trade depends on how heavily they weight consumption of timber and grain relative to species conservation. It also depends on the extent to which consumers value local versus global biodiversity. Suppose, for example that only global biodiversity is valued $(\mu=0, \theta>0)$, and further that species are shared between the two countries. Then consumers are unambiguously better off under free trade than under autarky (globally, more species exist under free trade in this case). At the other extreme, consider the case in which only local biodiversity matters $(\mu>0, \theta=0)$. Then consumers receive lower utility from species conservation under free trade, but they receive higher utility from private goods 
consumption. Whether they ultimately receive higher, or lower, overall utility under autarky or free trade depends on the relative strength of their preferences for species conservation versus consumption of private goods.

We have shown that even though utility from consumption must increase with free trade, it is possible for overall utility to decline. Trade leads to specialization in production that causes particular habitats to be heavily exploited, which leads to a decline in local biodiversity. Depending on the degree of endemism, global biodiversity may also decline. The loss of utility from species decline may more than offset the increase in utility from consumption gains meaning that free trade can lead to lower welfare. On the other hand, trade may increase welfare. This result is more likely to occur with a high degree of species overlap among trading partners (low endemism) or with low importance of species conservation relative to consumption of private goods.

\section{The socially optimal pattern of production}

In both autarky and free trade, the welfare effects of production on species conservation are ignored. Because of this both autarky and free trade equilibria are inefficient. Here we compare the socially optimal pattern of production and land use with that under autarky and free trade.

A social planner wishing to maximize the utility of individuals across the two countries (and assuming equal weights attached to each individual) faces the following problem:

$$
\max \sum_{i=1}^{2} \sum_{j=1}^{\bar{L}_{i}}\left(x_{i j}^{\alpha} y_{i j}^{1-\alpha}+\mu S_{i}+\theta S\right) \text {, }
$$

where $x_{i j}\left(y_{i j}\right)$ represents consumption of timber (grain) by individual $j$ in country $i$. Noting that the marginal rates of substitution for all individuals must be equalized in an optimal solution, and that total consumption must equal total production, we can rewrite the maximization problem as

$$
\max X^{\alpha} Y^{1-\alpha}+\bar{L}_{1} \mu S_{1}+\bar{L}_{2} \mu S_{2}+\left(\bar{L}_{1}+\bar{L}_{2}\right) \theta S .
$$

Then using the definition of the production functions and the species-area curve relationships, the maximization problem can be written in terms of labor (and land) allocation:

$$
\begin{aligned}
& \max \left(a_{1} L_{F 1}+a_{2} L_{F 2}\right)^{\alpha}\left(b_{1} L_{G 1}+b_{2} L_{G 2}\right)^{1-\alpha} \\
& \quad+\bar{L}_{1} \mu\left[\phi_{1}\left(T_{F 1}-L_{F 1}\right)+\gamma_{1}\left(T_{G 1}-L_{G 1}\right)\right] \\
& \quad+\bar{L}_{2} \mu\left[\phi_{2}\left(T_{F 2}-L_{F 2}\right)+\gamma_{2}\left(T_{G 2}-L_{G 2}\right)\right] \\
& \quad+\left(\bar{L}_{1}+\bar{L}_{2}\right) \theta\left[\phi_{1}\left(T_{F 1}-L_{F 1}\right)+\gamma_{1}\left(T_{G 1}-L_{G 1}\right)+\phi_{2}\left(T_{F 2}-L_{F 2}\right)+\gamma_{2}\left(T_{G 2}-L_{G 2}\right)\right] .
\end{aligned}
$$

Let $\lambda_{i} \geqslant 0$ represent the Lagrange multiplier on the constraints that labor applied not exceed population: $L_{G i}+L_{F i} \leqslant \bar{L}_{i}$. Let $\eta_{i} \geqslant 0$ represent the multiplier on the non-negativity constraint on $L_{G i}$ and $\psi_{i} \geqslant 0$ represent the multiplier on the non-negativity constraint on $L_{F i}$. Then, the firstorder conditions for an optimal solution are:

$$
\frac{\alpha a_{i} c}{X}-\left[\bar{L}_{i} \mu+\left(\bar{L}_{1}+\bar{L}_{2}\right) \theta\right] \phi_{i}^{\prime}\left(T_{F i}-L_{F i}\right)-\lambda_{i}+\psi_{i}=0
$$




$$
\frac{(1-\alpha) b_{i} c}{Y}-\left[\bar{L}_{i} \mu+\left(\bar{L}_{1}+\bar{L}_{2}\right) \theta\right] \gamma_{i}^{\prime}\left(T_{G i}-L_{G i}\right)-\lambda_{i}+\eta_{i}=0,
$$

where $c\left(\equiv X^{\alpha} Y^{1-\alpha}\right)$ is the utility from consumption. In this model, neither the specialization result or the full utilization of labor result necessarily hold when species conservation effects on utility are included. First note that if either $\mu$ or $\theta$ are large, the second term in Eqs. (14) and (15) are large in magnitude and negative. Therefore, $\lambda_{i}$ need not be positive but can be zero, which implies that the labor constraint need not bind. When the disutility from species loss is large, natural habitat is of greater value than increased consumption from production of timber or grain. In this case, some labor (and land) would be idled. This result only holds under the special case where land and labor are used in a fixed ratio. In a more general model that allowed for substitution of factors in production, a reduction in land use would cause a shift toward more labor intensive production methods rather than leaving labor idle. In other words, a shift on the extensive margin from reduced land in production would cause a shift on the intensive margin toward greater labor use per unit of land in production. Even in the general model, the inclusion of conservation objectives would lead to a reduction in the value of overall production.

Next, note that it is possible for it to be optimal for each country to produce some positive amount of both goods (i.e., when either $\mu$ or $\theta$ are large both $\eta_{i}$ and $\psi_{i}$ may be zero). There is an opportunity cost of production of each good in each country, which is caused by the loss of species from habitat loss. Therefore, it may be optimal to use a little of each type of habitat, moving along the relatively flat part of the species-area curve relationship, but not to use a great deal of any type of habitat as would be required by specialization, thereby avoiding moving down the steep part of the species area curve.

In principle, implementing an optimal solution follows from well-understood economic principles. Land use that destroys habitat resulting in a decline in biodiversity causes an externality. One solution to this externality problem is to implement a Pigouvian tax on land use conversion that reflects the marginal damage from species loss. Setting the proper tax requires knowledge of the marginal utility of conserving species as well as the species-area relationship, i.e., requires knowledge of both economic and ecological relationships. Such a tax would vary with the level of habitat destruction. The tax would tend to be low in cases for habitat types that are relatively plentiful but would rise as habitat became scarce. Other instruments besides a tax on land use could also be used. Setting aside certain lands for conservation, zoning laws regulating acceptable land uses, or tradable development rights could all be used to provide an efficient solution, at least in theory. As with the land use tax, to be effective policy-makers would require a great deal of knowledge about both economic and ecological relationships.

Addressing the externality problem can be accomplished in the case of autarky as well. Taxes on land use or quantity instruments such as tradable development rights could be used to shift production and land use within a country. Note that because specialization would not occur in autarky, it may be less crucial to have corrective conservation policy in place. Though even here it may be important to protect certain habitats or to send the proper signal to producers of the relative importance of habitat conservation. If each country had an efficient conservation policy in place in autarky, then a move to free trade would be unambiguously welfare improving. 


\section{Conclusions and discussion}

In this paper, we linked a simple two-country two-good trade model with species-area curves to demonstrate the effects of trade on the pattern of production across countries, habitat conversion, species assemblages, consumption and utility. Trade can have adverse consequences for biodiversity for precisely the reason it is attractive: exploiting comparative advantage resulting in specialization. To the extent that ecosystems are aligned with production systems, specialization in production means that conversion of habitat will be focused on certain types of ecosystems. Because of the concavity of species-area relationships, such specialization can lead to severe declines in the number of species conserved. When there is a high degree of species endemism, or where local biodiversity as opposed to global biodiversity is of greater concern, trade can reduce welfare. On the other hand, when trading partners have large overlap in species and what is of concern is global rather than local biodiversity, trade is unambiguously beneficial. Taking biodiversity conservation concerns into account may lead to changes in the pattern of production and trade. These may include restricting land use to maintain habitat and reducing the extent of specialization, even though both changes tend to reduce the value of production. Examples of important cases where trade leading to specialization may have concentrated habitat destruction on particular habitats include tropical forests where virtually all demand for the tropical timber comes from abroad. The almost complete conversion of Midwestern grasslands in the US may also be enhanced by the ability to export grains.

The model we developed in this paper was kept quite simple in order to make clear the basic logic of how trade can affect biodiversity conservation. Our model focused on the effect of trade on the location of production, which determines the pattern of habitat destruction across countries. While this effect is important, it is not the only effect of trade on biodiversity. Trade can also change demand through an income effect, which may have important environmental consequences. Trade may also influence relative input prices, which can lead to changes in the techniques of production. For example, moving to more intensive agricultural production methods capable of growing more grain per hectare can reduce demand on land and spare natural habitat. Allowing for more substitution effects among factor inputs would allow one to incorporate this effect.

Trade also influences local and global biodiversity directly through the introduction of nonindigenous species. Open trade flows serve as a platform for biological invasions of exotic species. Exotic species hitchhike on shipments of traded goods and on occasion successfully invade new areas. Local biodiversity can either increase (if exotic species do not substantially impact native species) or decrease (if exotic species negatively impact native species) with these introductions. Global biodiversity will decline with introductions of non-indigenous species whenever there is a negative impact on native species and those native species are endemic.

There are a number of other ways that the model could be enriched, both on the economic side and on the ecology side. We restricted land parcels to be capable of producing only one type of good, which correlated perfectly with one type of habitat. In reality, land parcels generally are capable of producing different goods. For example, a forest could be cleared so that crops could be planted. One could specify the capability of each land parcel for producing each particular good rather than assuming it can only produce a single good. Expanding the model in this way allows for some substitution among land parcels of different habitat types meaning that an 
increase in specialization in production need not necessarily be concentrated so heavily on a single type of habitat.

The assumption that species can only utilize natural habitat is also too restrictive. Certain species are known to persist on working landscapes (agricultural fields and managed forests). It is often possible to change production methods or land management in ways to ameliorate the negative impacts of production on biodiversity. In addition, other factors beyond just habitat area, such as habitat quality, fragmentation and connectivity, also matter for species survival probabilities. A more realistic model would involve specifying survival probabilities of species as a function of the pattern of natural and managed landscapes and the practices used on managed landscapes.

We have modeled utility as a function of private consumption and local and global species richness. It is equally plausible that alternative measures of biodiversity enter the utility function. For example, individual species or groups of species may be inputs to the production of ecosystem services, which themselves have value. Alternatively, we may be interested in genetic diversity, rather than simply species richness. Including these as arguments of utility would require a different objective function, but would not qualitatively alter the results of this paper. A third possibility that may have important consequences is that people obtain systematically different utility from different species. Charismatic megafauna, the lions, tigers and bears of the world, often require large tracts of undisturbed habitat and are therefore often the first to be extirpated from ecosystems converted for human use. In that case, even small amounts of conversion can cause large utility declines, a result that tends to favor specialization over diversification of production in each country.

Enriching both the economic and ecological sides of the model could add insights and greater realism to the analysis of the links between trade and biodiversity conservation. Specifically directing policy on the basis of this work will require going beyond the simple model presented here in ways outlined in the prior paragraphs as well as others. These more complex models, however, would still contain the basic insights on how trade can affect biodiversity conservation, either directly through importation of exotic species, or indirectly through the changes in relative returns that affects land use and habitat, that we have emphasized in this paper.

\section{References}

[1] K. Anderson, The standard welfare economics of policies affecting trade and the environment, in: K. Anderson, R. Blackhurst (Eds.), The Greening of World Trade Issues, Harvester Wheatsheaf, Hemel Hempstead, UK, 1992.

[2] A. Ando, J. Camm, S. Polasky, A. Solow, Species distributions, land values, and efficient conservation, Science 279 (1998) 2126-2128.

[3] G. Arthaud, D. Rose, A methodology for estimate production possibility frontiers for wildlife habitat and timber value at the landscape level, Can. J. Forest Res. 26 (1996) 2191-2200.

[4] E. Barbier, C. Shulz, Wildlife, biodiversity and trade, Environ. Devel. Econ. 2 (2) (1997) 145-172.

[5] J. Brander, M. Taylor, Open access renewable resources: trade and trade policy in a two-country model, J. Int. Econ. 44 (2) (1998) 181-209.

[6] D. Calkin, C. Montgomery, N. Schumaker, S. Polasky, J. Arthur, D. Nalle, Developing a production possibility set of wildlife species persistence and timber harvest value using simulated annealing, Can. J. Forest Res. 32 (2002) 1329-1342.

[7] G. Chichilnisky, North-south trade and the global environment, Amer. Econ. Rev. 84 (4) (1994) $851-874$. 
[8] B. Copeland, M. Taylor, Trade and transboundary pollution, Amer. Econ. Rev. 85 (4) (1995) 716-737.

[9] D. Faith, Conservation evaluation and phylogenetic diversity, Biol. Conservat. 61 (1992) 1-10.

[10] R. Haight, Comparing extinction risk and economic cost in wildlife conservation planning, Ecol. Appl. 5 (1995) 767-775.

[11] A. Hector, B. Schmid, C. Beierkuhnlein, M. Caldeira, M. Diemer, P. Dimitrakopoulos, J. Finn, H. Freitas, P. Giller, J. Good, R. Harris, P. Hgberg, K. Huss-Danell, J. Joshi, A. Jumpponen, C. Krner, P.W. Leadley, M.L.A. Minns, C. Mulder, G. O’Donovan, S. Otway, J. Pereira, A. Prinz, D. Read, M. Scherer-Lorenzen, E. Schulze, A. Siamantziouras, E. Spehn, A. Terry, A. Troumbis, F. Woodward, S. Yachi, J. Lawton, Plant diversity and productivity experiments in European grasslands, Science 286 (1999) 1123-1127.

[12] W. Hyde, Marginal costs of managing endangered species: the case of the red-cockaded woodpecker, J. Agr. Econ. Res. 41 (2) (1989) 12-18.

[13] R. Kohn, P. Capen, Optimal volume of environmentally damaging trade, Scottish J. Polit. Economy 49 (1) (2002) 22-38.

[14] S. Levin, Fragile Dominion: Complexity and the Commons, Perseus Books, Reading, MA, 1999.

[15] M. Lichtenstein, C. Montgomery, Biodiversity and timber in the Coast Range of Oregon: inside the production possibility frontier, Land Econ. 79 (1) (2003) 56-73.

[16] M. Loreau, S. Naeem, P. Inchausti, J. Bengtsson, J. Grime, A. Hector, D. Hooper, M. Huston, D. Raffaelli, B. Schmid, D. Tilman, D. Wardle, Biodiversity and ecosystem functioning: current knowledge and future challenges, Science 294 (2001) 804-808.

[17] R. MacArthur, E. Wilson, The Theory of Island Biogeography, Princeton University Press, Princeton, NJ, 1967.

[18] E. Marshall, F. Homans, R. Haight, Exploring strategies for improving the cost effectiveness of endangered species management, Land Econ. 76 (3) (2000) 462-473.

[19] C. Montgomery, G. Brown, R. Adams, The marginal cost of species preservation: the northern spotted owl, J. Environ. Econ. Manag. 26 (1994) 111-128.

[20] C. Montgomery, R. Pollak, K. Freemark, D. White, Pricing biodiversity, J. Environ. Econ. Manag. 38 (1) (1999) $1-19$.

[21] N. Myers, R. Mittermeier, C. Mittermeier, G. da Fonseca, J. Kent, Biodiversity hotspots for conservation priorities, Nature 403 (2000) 853-858.

[22] S. Naeem, S. Li, Biodiversity enhances ecosystem reliability, Nature 390 (1997) 507-509.

[23] S. Naeem, L. Thompson, S. Lawler, J. Lawton, R. Woodfin, Declining biodiversity can alter the performance of ecosystems, Nature 368 (1994) 734-737.

[24] D. Nalle, C. Montgomery, J. Arthur, S. Polasky, N. Schumaker, Modeling joint production of wildlife and timber in forests, J. Environ. Econ. Manag., in review.

[25] National Research Council, Science and the Endangered Species Act, National Academy Press, Washington, DC, 1995.

[26] S. Pimm, G. Russell, J. Gittleman, T. Brooks, The future of biodiversity, Science 269 (1995) 347-350.

[27] S. Polasky, J. Camm, B. Garber-Yonts, Selecting biological reserves cost effectively: an application to terrestrial vertebrate conservation in Oregon, Land Econ. 77 (2001) 68-78.

[28] M. Rauscher, International Trade, Factor Movements, and the Environment, Clarendon Press, Oxford, UK, 1997.

[29] F. Samson, F. Knopf, W. Ostlie, Grasslands, in: Status and Trends of the Nation's Biological Resources, Mac, Opler, Puckett Haecker and Doran, 1998, pp. 437-472.

[30] D. Simpson, R. Sedjo, J. Reid, Valuing biodiversity for use in pharmaceutical research, J. Polit. Economy 104 (1996) $163-185$.

[31] A. Solow, S. Polasky, Measuring biological diversity, Environ. Ecol. Statist. 1 (2) (1994) 95-107.

[32] D. Tilman, J. Downing, Biodiversity and stability in grasslands, Nature 367 (1994) 363-365.

[33] D. Tilman, J. Knops, D. Wedin, P. Reich, M. Ritchie, E. Siemann, The influence of functional diversity and composition on ecosystem processes, Science 277 (1997) 1300-1302.

[34] D. Tilman, P. Reich, J. Knops, D. Wedin, T. Mielke, C. Lehman, Diversity and productivity in a long-term grassland experiment, Science 294 (2001) 843-845.

[35] D. Tilman, D. Wedin, J. Knops, Productivity and sustainability influenced by biodiversity in grassland ecosystems, Nature 379 (1996) 718-720. 
[36] United States Fish \& Wildlife Service, Species information: Threatened and endangered animals and plants, World Wide Web: http://endangered.fws.gov/wildlife.html\#Species, 2002.

[37] M. Weitzman, On diversity, Quart. J. Econ. 102 (1992) 363-405.

[38] D. Wilcove, D. Rothstein, J. Dubow, A. Philips, E. Losos, Quantifying threats to imperiled species in the United States, BioScience 48 (1998) 607-615.

[39] E.O. Wilson, Biodiversity, National Academy Press, Washington, DC, 1988.

[40] E.O. Wilson, The Diversity of Life, W.W. Norton \& Co., New York, 1992. 